\title{
Active and Reactive Power Control of a Dual Stator Induction Machine (DSIM) using PI Controllers
}

\author{
Fatma Lounas ${ }^{1}$, Salah Haddad ${ }^{2}$, Nacereddine Benamrouche ${ }^{3}$ \\ 1, 2,3 Department of Electrical Engineering, Laboratory of Advanced Technology of Electrical Engineering \\ (LATAGE) Mouloud Mammeri University, Tizi Ouzou, Algeria
}

\begin{tabular}{l}
\hline \hline Article Info \\
\hline Article historys: \\
Received Jun 27, 2019 \\
Revised Nov 8, 2019 \\
Accepted Dec 20, 2019 \\
\hline
\end{tabular}

\section{Keywords:}

Dual Stator Induction Machine Active power

Reactive power

Field Oriented Control

PI controller

\begin{abstract}
In this paper, we present the active and reactive power control of a Dual Stator Induction Generator (DSIG). Contrary to the Doubly Fed Induction Generator (DFIG), which is controlled by its rotor and which delivers power from its stator, in the DSIG, one of the two stator windings plays the role of control winding and the other plays that of the power winding. The aim of this article is to establish, using some simplifying assumptions, the relationships between the active and the reactive powers delivered from the power winding and the voltages applied at its control winding terminals. Based on these relationships, a functional diagram is built and the active and reactive power regulators are synthesized. A model of the controlled DSIG is implemented under MATLAB-Simulink environment and the simulation results showed the feasibility and the performances of the developed control laws.
\end{abstract}

Copyright $@ 2019$ Institute of Advanced Engineering and Science. All rights reserved.

\section{Corresponding Author:}

Fatma Lounas,

Department of Electrical Engineering,

Mouloud Mammeri University,

Tizi Ouzou, 15000, Algeria.

Email: fat_lounas@yahoo.fr

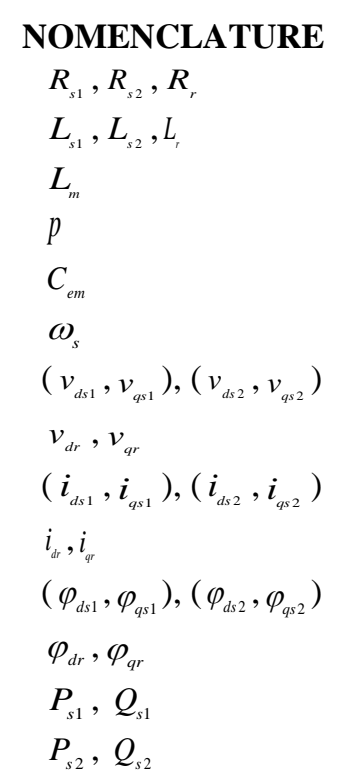

stator 1 , stator 2 and rotor resistances.

stator 1 , stator 2 and rotor inductances.

magnetizing inductance.

number of pole pairs.

electromagnetic torque

angular speed

$\mathrm{d}$ and $\mathrm{q}$ components of stator 1 and stator 2 voltages

$\mathrm{d}$ and $\mathrm{q}$ components of rotor voltage.

$\mathrm{d}$ and $\mathrm{q}$ components of stator 1 and stator 2 currents

$\mathrm{d}$ and $\mathrm{q}$ components of rotor current

$\mathrm{d}$ and q components of stator 1 and stator 2 flux.

$\mathrm{d}$ and $\mathrm{q}$ components of rotor flux.

active and reactive power of stator 1

active and reactive power of stator 2 


\section{INTRODUCTION}

In recent years and with the progress of science and technology, the global energy consumption continues to grow, the conventional sources of energy are limited and a number of problems are associated with their use such as environmental pollution. It is of great importance to develop clean and renewable energy to replace these traditional energy sources [1]. Among renewable energy resources, wind energy is considered as one of the most promising and important sources of renewable energy in the world, mainly because it is clean, cost-effective, renewable, and harmless to the environment and also for its contribution to the reduction of $\mathrm{CO}_{2}$ emissions [2].

The permanent magnet synchronous generator (PMSG) plays a significant role in the wind energy conversion [3]. However, the high cost of the permanent magnets present in the rotor as well as its risk of demagnetization at high temperatures, limit the use of these machines [4].

Due to its many advantages, the DFIM became a good candidate for variable speed wind energy conversion systems [5] and for high power drive systems [6]. Nevertheless, the presence of the slip rings and the brush system in the DFIM reduces its reliability, its robustness and requires periodical maintenance [7].

Since the beginning of the 20th century, many studies have been carried out in order to develop a machine that could overcome these disadvantages. The Dual Stator Induction Machine (DSIM) has become an attractive option particularly for renewable energy systems. This type of multiphase machines has several advantages over the other types of induction machines, such as power segmentation, torque ripples minimization and rotor current harmonics reduction[8-10]. The DSIM is an alternative solution for conventional Doubly Fed Induction Machines (DFIM) replacement. In fact, its configuration retains all the benefits of the wound rotor induction machine in a brushless structure. It provides robustness, reliability and low maintenance cost.

Brushless Doubly Fed Induction Generator (BDFIG) has been the subject of several studies. A vector control scheme is developed, including an experimental implementation in [11]. Comparison of control strategies for a novel Dual-Stator Brushless Doubly-Fed Induction Generator in wind energy applications is given in [12]. In [13] a Predictive Power Control Model (PPCM) of a Brushless Doubly Fed Twin Stator Induction Generator is presented. In [14] we find the fuzzy logic control strategy of wind generator based on the Dual-Stator Induction Generator.

Many research works have reported power control techniques for controlling the active and reactive power flow independently [15]. Stator flux-oriented vector control scheme has been proposed for active and reactive powers in a DFIG-based wind energy conversion system in [16]. Active and Reactive Power Control of a DFIG for Variable Speed Wind Energy Conversion is presented in [17], [18], [19]. In [20] direct and indirect control of a Doubly Fed Induction Generator wind turbine including a storage unit is developed. [21] treats a power control study of a wind energy conversion system based on a Doubly Fed Induction Generator (DFIG) connected to the electric power grid. Real-time active and reactive power control of a Doubly-Fed Induction Generator based wind energy conversion system is studied in [22]. The performance of a PI controller for active and reactive power control of a DFIG operating in a grid-connected variable speed wind energy conversion system is given in [23]. A comparative study between the use of PI and PID controllers for the control of the active and reactive power of a DFIG based wind energy conversion system is given in [24].

Most of the work that dealt with power control of induction generators is based on the exploitation of functional diagrams. These diagrams were already well established for the DFIM and for the cascade of DFIM. However, for the DSIM, they did not take into account the coupling which exists between the power winding and the control winding.

In this work, we propose to take this coupling into account and to develop, under certain simplifying assumptions, the relationships between the active and reactive powers delivered by the DSIM from its power winding and the voltages of its control winding, in order to synthesize PI controllers.

This paper is organized into six sections. The description of the studied system is given in Section 2. The modeling of the Dual Stator Induction Machine is presented in Section 3. Section 4 is dedicated to the active and reactive power control of the DSIM. In Section 5 the simulation results are presented and discussed. Section 6 contains the conclusion.

\section{SYSTEM DESCRIPTION}

Figure 1 shows the structure of the proposed system. The Dual Stator Induction Generator has two windings in the stator; stator 1 represents the power winding (PW) connected directly to the grid and stator 2 is the control winding $(\mathrm{CW})$, it is connected to the grid through a bidirectional converter. The rotor is a squirrel cage type.

The two stator windings of the DSIG have the same number of poles. Assuming that the reference frame is aligned with stator 1 flux, the active and the reactive powers exchanged between stator 1 (power winding) of the DSIG and the grid are controlled independently by using classical Proportional Integral (PI) 
controllers. Bidirectional converters allowing bidirectional power flow are used. This capability is used to operate the DSIG in both hyper-synchronous and hypo-synchronous modes.

\section{MODELING OF THE DUAL STATOR INDUCTION MACHINE}

The dual stator induction machine is composed of two fixed three-phase stator windings denoted as stator 1 and stator 2 shifted by an electrical angle $\alpha$, and a common squirrel cage mobile rotor [8] as shown in Figure 2.

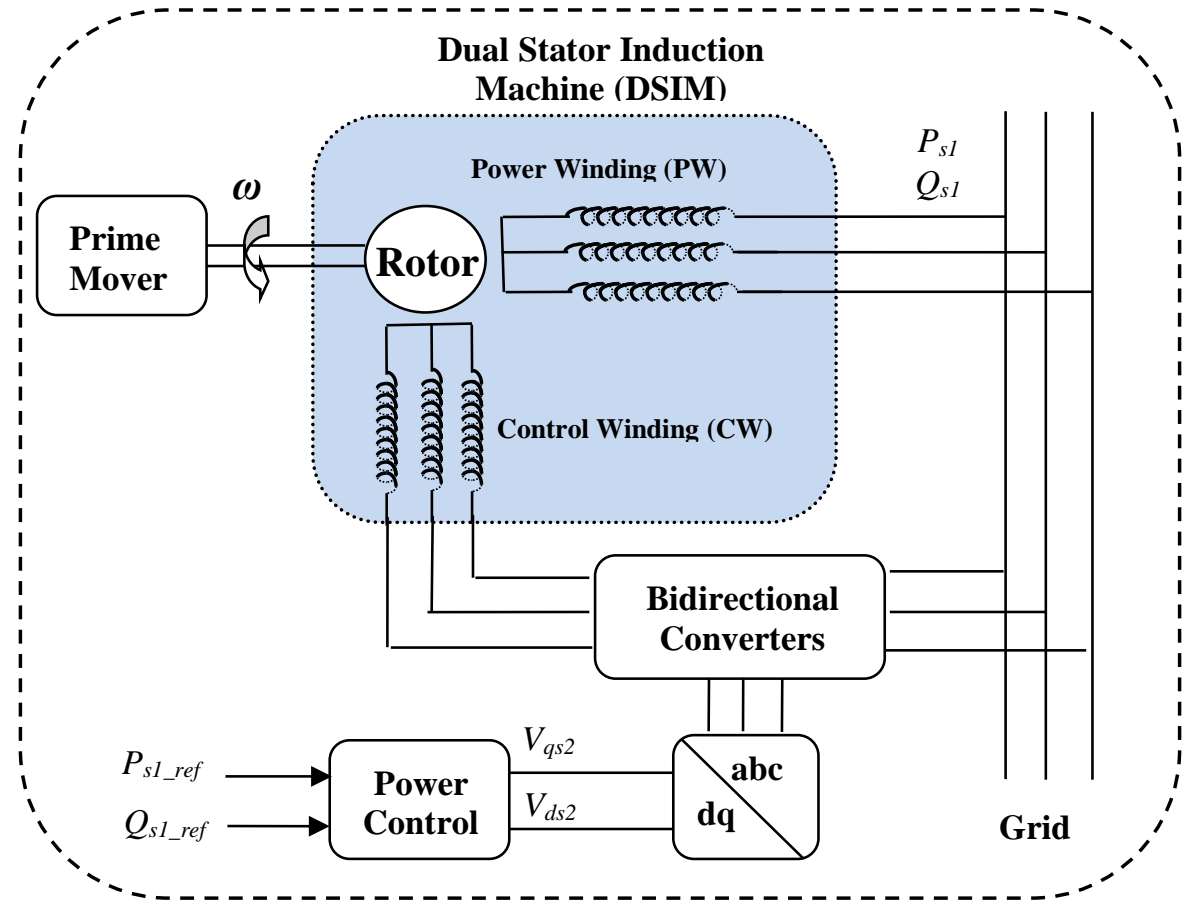

Figure 1. Synoptic scheme of the studied system

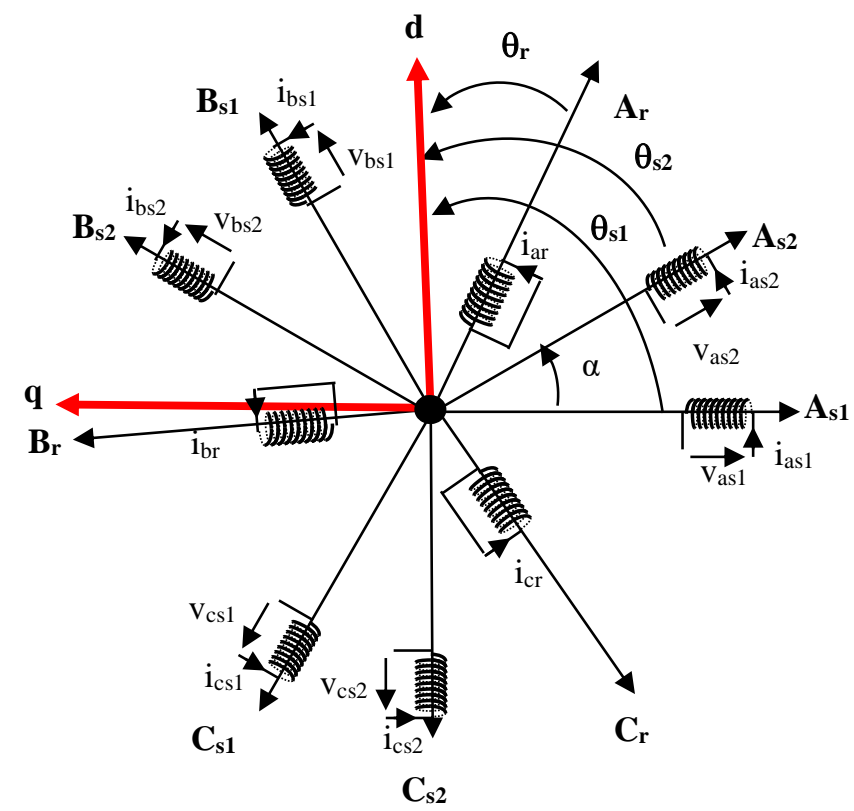

Figure 2. Electrical diagram of the windings of a Dual Stator Induction Machine

The voltage and flux equations describing the dual stator induction machine model in an arbitrary reference frame are as follows: 
Stator 1

$$
\begin{aligned}
& \left\{\begin{array}{l}
v_{d s 1}=R_{s 1} i_{d s 1}+\frac{d \varphi_{d s 1}}{d t}-\frac{d \theta_{s 1}}{d t} \cdot \varphi_{q s 1} \\
v_{q s 1}=R_{s 1} i_{q s 1}+\frac{d \varphi_{q s 1}}{d t}+\frac{d \theta_{s 1}}{d t} \cdot \varphi_{d s 1}
\end{array}\right. \\
& \left\{\begin{array}{l}
\varphi_{d s 1}=\left(L_{s 1}+L_{m}\right) i_{d s 1}+L_{m}\left(i_{d s 2}+i_{d r}\right) \\
\varphi_{q s 1}=\left(L_{s 1}+L_{m}\right) i_{q s 1}+L_{m}\left(i_{q s 2}+i_{q r}\right)
\end{array}\right.
\end{aligned}
$$

Stator 2

$$
\begin{aligned}
& \left\{\begin{array}{l}
v_{d s 2}=R_{s 2} \cdot i_{d s 2}+\frac{d \varphi_{d s 2}}{d t}-\frac{d \theta_{s 2}}{d t} \cdot \varphi_{q s 2} \\
v_{q s 2}=R_{s 2} \cdot i_{q s 2}+\frac{d \varphi_{q s 2}}{d t}+\frac{d \theta_{s 2}}{d t} \cdot \varphi_{d s 2}
\end{array}\right. \\
& \left\{\begin{array}{l}
\varphi_{d s 2}=\left(L_{s 2}+L_{m}\right) i_{d s 2}+L_{m}\left(i_{d s 1}+i_{d r}\right) \\
\varphi_{q s 2}=\left(L_{s 2}+L_{m}\right) i_{q s 2}+L_{m}\left(i_{q s 1}+i_{q r}\right)
\end{array}\right.
\end{aligned}
$$

Rotor

$$
\begin{aligned}
& \left\{\begin{array}{l}
v_{d r}=R_{r} \cdot i_{d r}+\frac{d \varphi_{d r}}{d t}-\frac{d \theta_{r}}{d t} \varphi_{q r}=0 \\
v_{q r}=R_{r} \cdot i_{q r}+\frac{d \varphi_{q r}}{d t}+\frac{d \theta_{r}}{d t} \cdot \varphi_{d r}=0
\end{array}\right. \\
& \left\{\begin{array}{l}
\varphi_{d r}=\left(L_{r}+L_{m}\right) i_{d r}+L_{m}\left(i_{d s 1}+i_{d s 2}\right) \\
\varphi_{q r}=\left(L_{r}+L_{m}\right) i_{q r}+L_{m}\left(i_{q s 1}+i_{q s 2}\right)
\end{array}\right.
\end{aligned}
$$

The torque equation is represented as follows:

$$
C_{e m}=p \frac{L_{m}}{L_{r}+L_{m}}\left[\left(i_{q s 1}+i_{q s 2}\right) \varphi_{d r}-\left(i_{d s 1}+i_{d s 2}\right) \varphi_{q r}\right]
$$

We consider in this work that DSIM works only in generator mode; in this case stator 1 and stator 2, which have the same number of pole pairs, they have necessarily the same frequency. Indeed, stator 2 whose pulsation is equal to $\omega_{s 2}$ induces in the rotor a field of pulsation equal to $g * \omega_{s 2}$. This rotor field is driven at the rotor speed. This induces in stator 1 a field with pulsation equal to the sum of the rotor field pulsation and the rotor speed $\Omega_{r}$.

$g * \omega_{s 2}=\omega_{s 2}-p * \Omega_{r}$, where $g$ is the slip.

$\omega_{s 1}=g * \omega_{s 2}+p * \Omega_{r}=\omega_{s 2}-p * \Omega_{r}+p * \Omega_{r}=\omega_{s 2}$

$\omega_{s 1}=\omega_{s 2}=\omega_{s}$.

\section{ACTIVE AND REACTIVE POWER CONTROL OF THE DUAL STATOR INDUCTION MACHINE}

\subsection{Field oriented control of the Dual Stator Induction Generator}

Assuming that the $(d, q)$ reference frame is linked to the rotating field and synchronized with the stator 1 flux, such as the $d$ axis is aligned with stator 1 flux, the $d$ axis stator 1 flux component is then always kept constant and the $q$ axis component is constantly equal to zero. 


$$
\left\{\begin{array}{l}
\varphi_{d s 1}=\varphi_{s} \\
\varphi_{q s 1}=0
\end{array},\left\{\begin{array}{l}
\frac{d \varphi_{d s 1}}{d t}=0 \\
\varphi_{q s 1}=0
\end{array}\right.\right.
$$

Stator 1 voltage equations become:

$$
\left\{\begin{array}{l}
v_{d s 1}=R_{s 1} \cdot i_{d s 1} \\
v_{q s 1}=R_{s 1} \cdot i_{q s 1}+w_{s} \cdot \varphi_{d s 1}
\end{array}\right.
$$

Assuming a stable electrical network with a constant voltage Vs, leads to a constant stator 1 flux. In addition, if we neglect the resistance of stator 1 (this is the case in wind energy conversion systems); stator 1 voltage equations are reduced to:

$$
\left\{\begin{array}{l}
v_{d s 1}=0 \\
v_{q s 1}=V_{s}=w_{s} \cdot \varphi_{d s 1}
\end{array}\right.
$$

Consequently, the equations of the rotor currents and those of stator 1 and stator 2 voltages and those of stator 1 powers are presented respectively in the set of the following equations (11-14).

$$
\begin{aligned}
& \left\{\begin{array}{l}
i_{d r}=-C i_{d r 2} \cdot-\frac{C V_{s}}{w_{s} \cdot L_{s 1}} \\
i_{q r}=-C \cdot i_{q 22}
\end{array}\right. \\
& \left\{i_{d s 1}=\left[\frac{L_{m}}{\left(L_{s 1}+L_{m}\right)}(C-1)\right] i_{d s 2}+\frac{V_{s}}{w_{s} \cdot\left(L_{s 1}+L_{m}\right)}\left[1+\frac{L_{m} \cdot C}{L_{s 1}}\right]\right. \\
& i_{q \mathrm{~s} 1}=\left[\frac{L_{m}}{\left(L_{\mathrm{s} 1}+L_{m}\right)}(C-1)\right] i_{d s 2}
\end{aligned}
$$

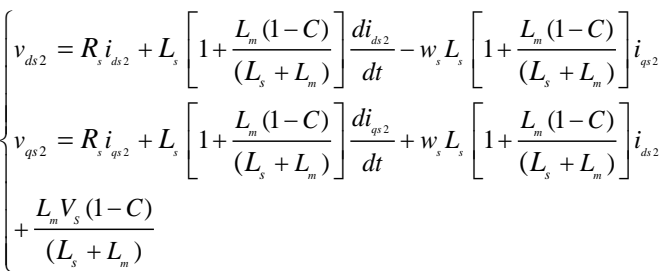

$$
\begin{aligned}
& \left\{\begin{array}{l}
P_{s 1}=V_{s} \cdot i_{q 1}=\frac{V_{s} \cdot L_{m}}{\left(L_{s}+L_{m}\right)}(C-1) i_{q<2} \\
Q_{s 1}=\left[\frac{V_{s} L_{m}}{\left(L_{s 1}+L_{m}\right)}(C-1)\right] i_{d \alpha 2}+\frac{V_{s}^{2}}{w_{s} \cdot\left(L_{s 1}+L_{m}\right)}\left[1+\frac{L_{m} \cdot C}{L_{s 1}}\right]
\end{array}\right.
\end{aligned}
$$

$$
\begin{aligned}
& \text { with } \\
& C=\left[\frac{L_{s 1} L_{m}}{\left(L_{r}+L_{m}\right) \cdot\left(L_{s 1}+L_{m}\right)-L_{m}{ }^{2}}\right]
\end{aligned}
$$

The dual stator induction machine diagram (Figure 3) derives from stator 2 voltages $\left(v_{d s 2}, v_{q 52}\right)$ and those of stator 1 active and reactive powers $\left(P_{s 1}, Q_{s 1}\right)$ given respectively by equations (13) and (14). 


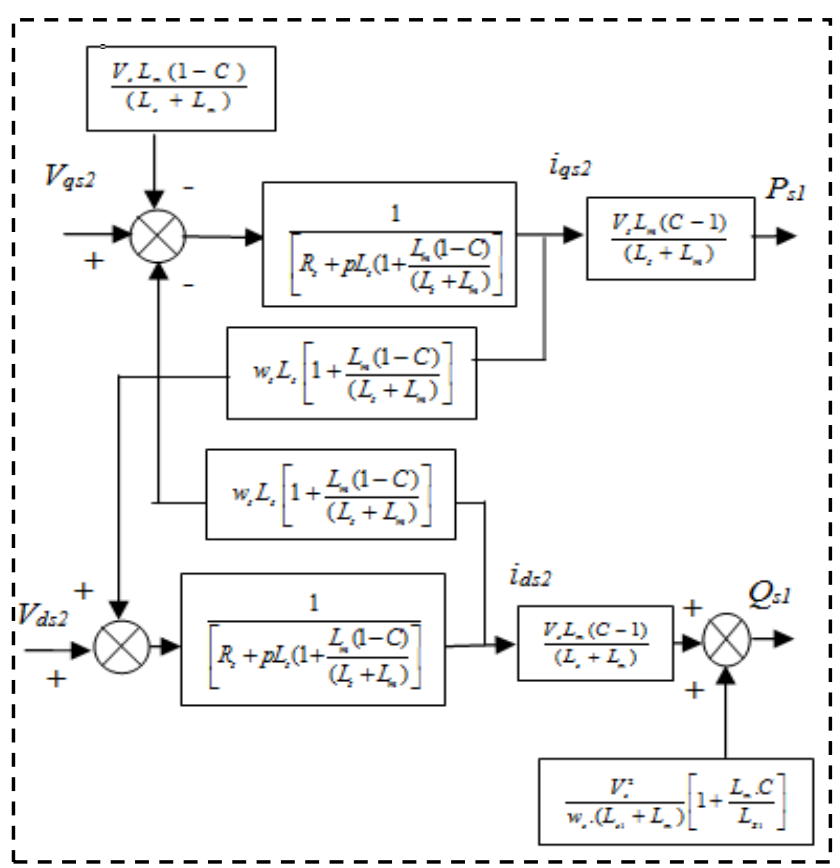

Figure 3. Simplified diagram of the Dual Stator Induction Machine

From this diagram, we can notice that stator 1 active and reactive powers are linked to stator 2 voltages by first order transfer functions.

\subsection{Active and reactive power control}

As shown in Figure 4, each power $\left(P_{s 1}\right.$ and $\left.Q_{s 1}\right)$ is controlled with an independent regulator. This is due to the fact that the coupling terms present in Figure 3 are compensated.

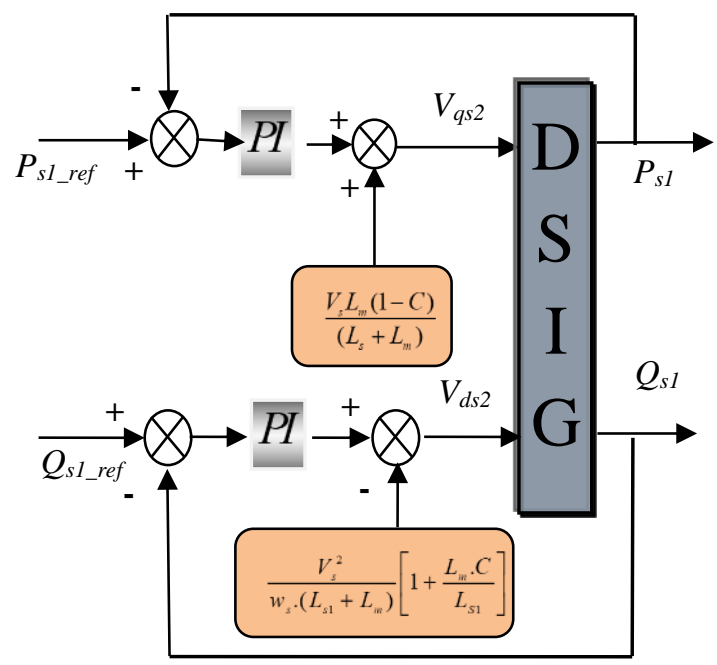

Figure 4. Block diagram of the power control

\subsection{PI regulators synthesis}

Figure 5 shows the structure of the PI controller used to regulate both the active and the reactive powers. The transfer function of the proportional integral controller is:

$$
G_{c}(p)=K_{P}+\frac{K_{i}}{p}
$$


The terms $K_{P}$ and $K_{i}$ are respectively the proportional and integral gains. These parameters are calculated using the well know a pole compensation method.

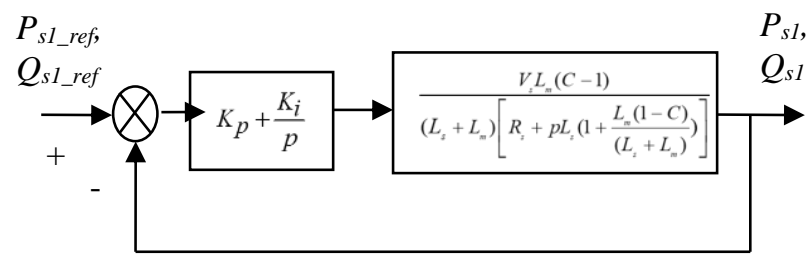

Figure 5. Structure of active and reactive power control loop

The open loop transfer function of the regulator is:

$$
G(p)=\left[\frac{p+\frac{K_{i}}{K_{p}}}{\frac{p}{K_{p}}}\left[\frac{\frac{V_{s} L_{m}(C-1)}{L_{s}\left(L_{s}+L_{m}\right)\left[1+\frac{L_{m}(1-C)}{\left(L_{s}+L_{m}\right)}\right]}}{\left.p+\frac{R_{s}}{L_{s}\left[1+\frac{L_{m}(1-C)}{\left(L_{s}+L_{m}\right)}\right]}\right]}\right]\right.
$$

Using the pole compensation method in order to eliminate the zero of the transfer function, we obtain the following relationship between the two controller gains:

$$
\frac{K_{i}}{K_{p}}=\frac{R_{s}}{L_{s}\left[1+\frac{L_{m}(1-C)}{\left(L_{s}+L_{m}\right)}\right]}
$$

The closed loop transfer function is expressed by:

$$
\begin{aligned}
& F(p)=\left[\frac{1}{1+\tau_{r} p}\right] \\
& \tau_{r}=\frac{L_{s}\left(L_{s}+L_{m}\right)\left[1+\frac{L_{m}(1-C)}{\left(L_{s}+L_{m}\right)}\right]}{K_{p} L_{m} V_{s}(C-1)}
\end{aligned}
$$

We can now express each controller gain as a function of the machine parameters and the desired time response $\tau_{r}$,

$$
\begin{aligned}
& K_{P}=\frac{L_{s}\left(L_{s}+L_{m}\right)\left[1+\frac{L_{m}(1-C)}{\left(L_{s}+L_{m}\right)}\right]}{\tau_{r} L_{m} V_{s}(C-1)} \\
& K_{i}=\frac{R_{s}\left(L_{s}+L_{m}\right)}{\tau_{r} L_{m} V_{s}(C-1)}
\end{aligned}
$$

\section{SIMULATION RESULTS AND DISCUSSION}

In order to study the performances of the proposed control method, a set of simulation tests are performed for a $1,1 \mathrm{~kW}$ DSIM. This DSIM is manufactured by "Electro-Industries" company, located at Azazga, Tizi Ouzou- Algeria. All the parameters of this machine are given in Table 1. The reactive power reference $Q_{s 1}$ is set to zero in order to obtain a unit power factor.

Table 1. The DSIM Parameters

\begin{tabular}{cc}
\hline DSIM nominal power & $\mathrm{P}_{\mathrm{n}}=1,1 \mathrm{~kW}$ \\
\hline Frequency & $f=50 \mathrm{~Hz}$ \\
Number of pole pairs & $\mathrm{p}=2$ \\
Stator resistances & $\mathrm{Rs} 1=\mathrm{Rs} 2=7.73 \Omega$ \\
Stator inductances & $\mathrm{Ls} 1=\mathrm{Ls} 2=0.0150 \mathrm{H}$ \\
Magnetizing inductance & $\mathrm{Lm}=0.44 \mathrm{H}$ \\
\hline
\end{tabular}

IJEEI, Vol.7, No. 4, Dec 2019: 664 - 676 
These tests are performed by applying three steps of the active power at different times $\left(\mathrm{P}_{1}=-200 \mathrm{~W}\right.$ at $\mathrm{t}_{1}=0 \mathrm{~s} ; \mathrm{P}_{2}=-1000 \mathrm{~W}$ at $\mathrm{t}_{2}=0.5 \mathrm{~s} ; \mathrm{P}_{3}=-600 \mathrm{~W}$ at $\mathrm{t}_{3}=1 \mathrm{~s}$,), the simulation results are presented for two operating modes of the DSIG, one below the synchronous speed (sub-synchronous mode) and one above (supersynchronous mode).

\subsection{Sub-synchronous mode}

In this case, it is assumed that the DSIG rotates below the synchronous speed $(1450 \mathrm{rpm})$, the simulation results characterizing this operating mode are represented in the figures below.

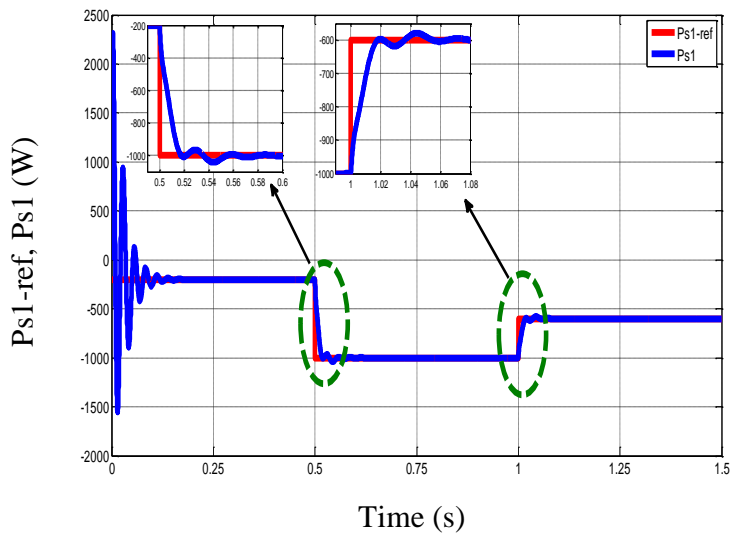

Figure 6. Active power of stator 1 and its reference

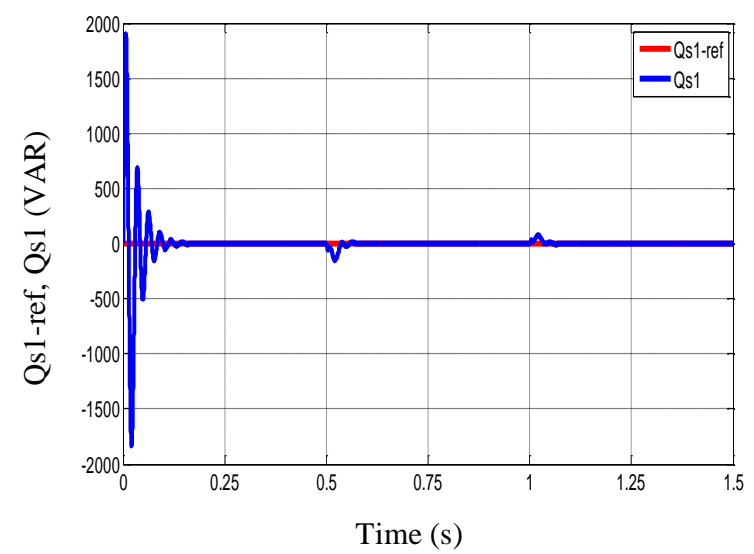

Figure 8 . Reactive power of stator 1 and its reference

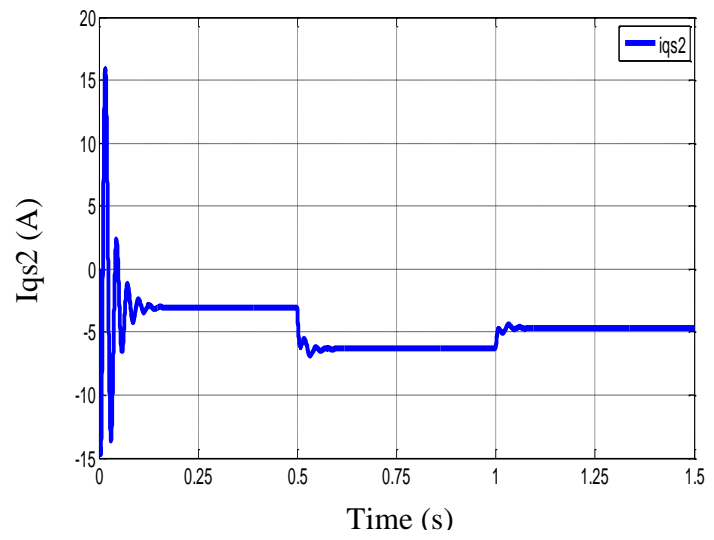

Figure 7. q-Component of stator 2 current

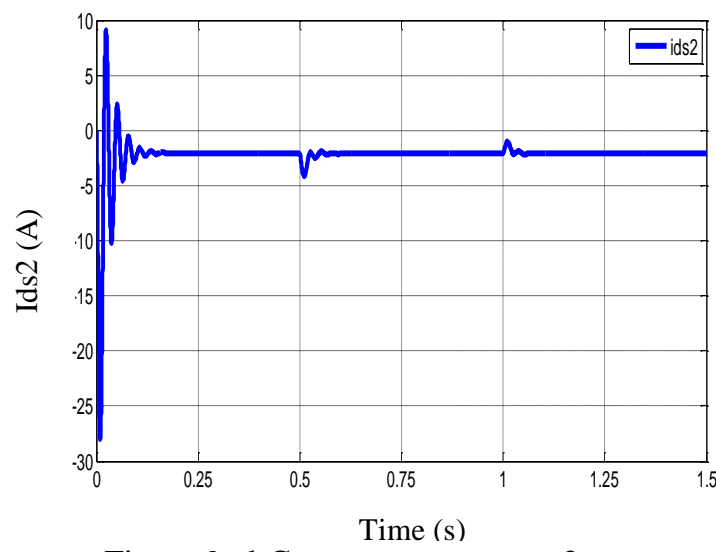

Figure 9. d-Component of stator 2 current

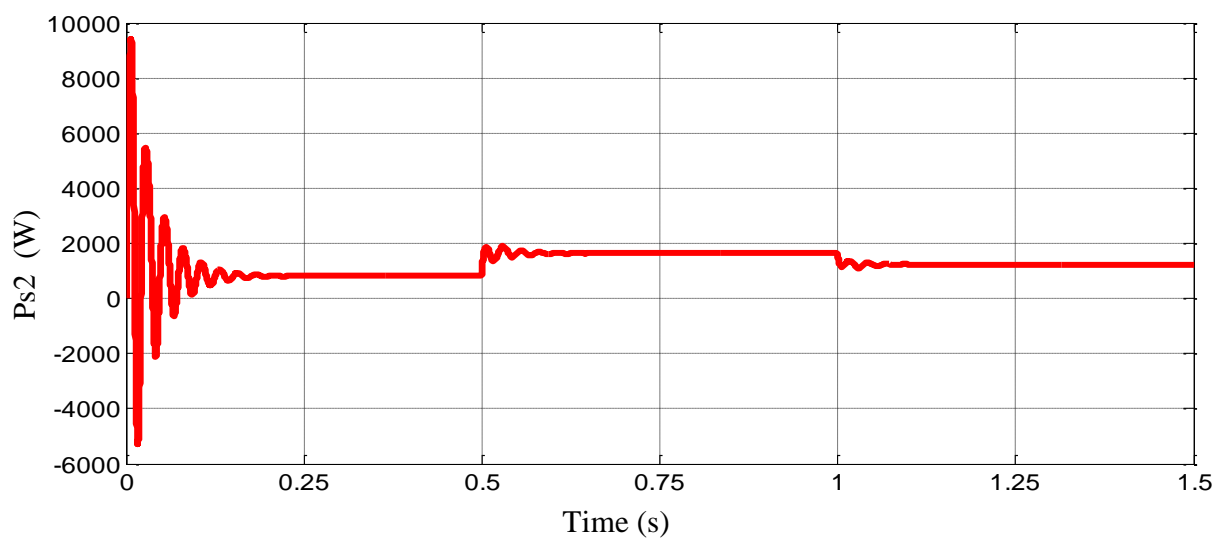

Figure 10. Active power of stator 2 


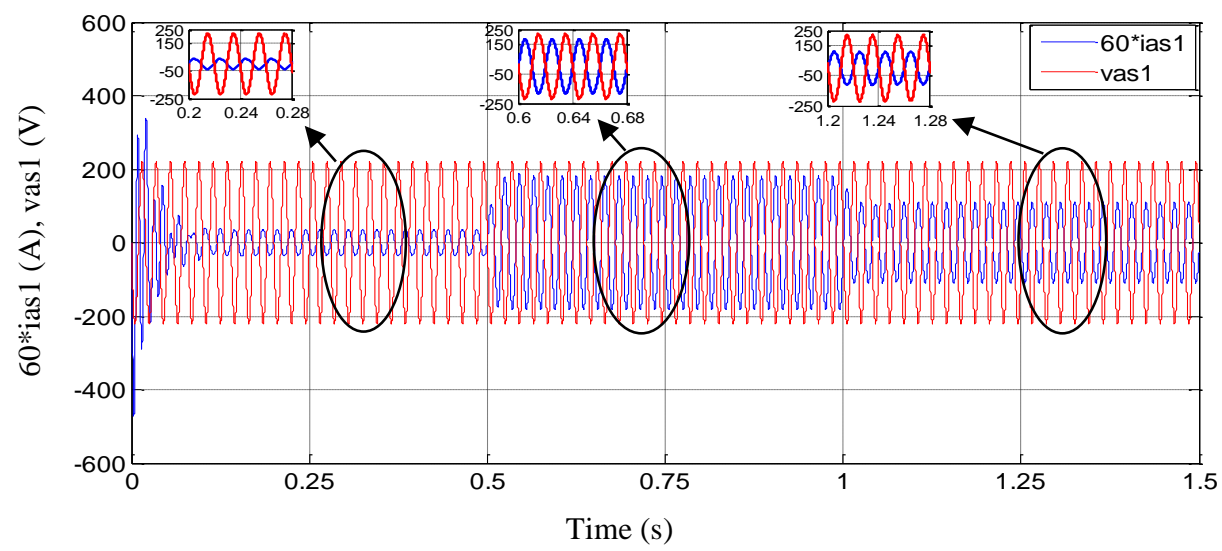

Figure 11. Current and voltage of stator 1

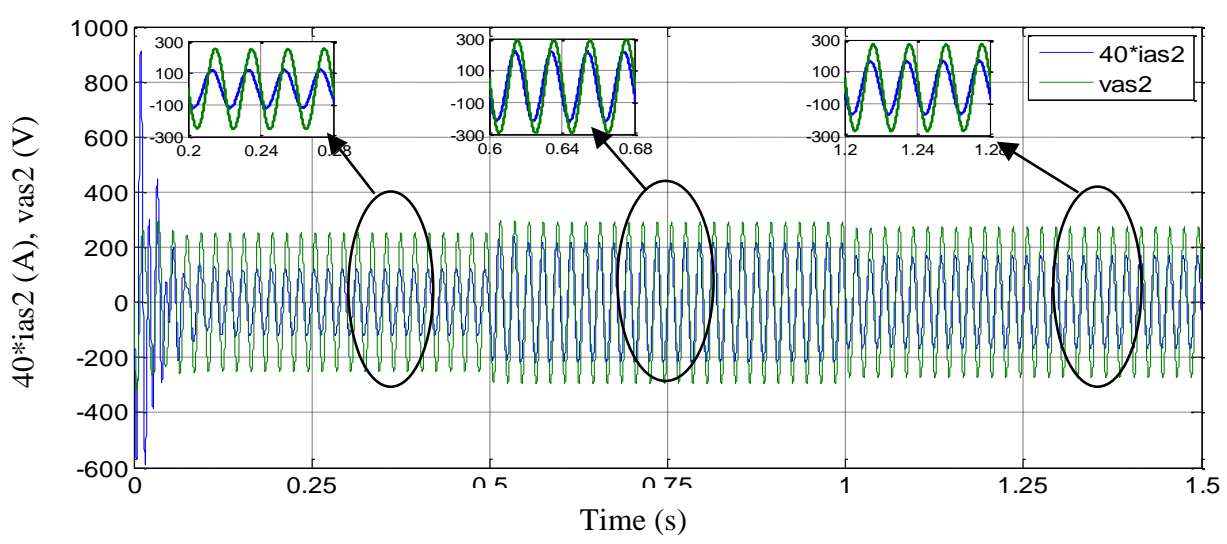

Figure 12. Current and voltage of stator 2

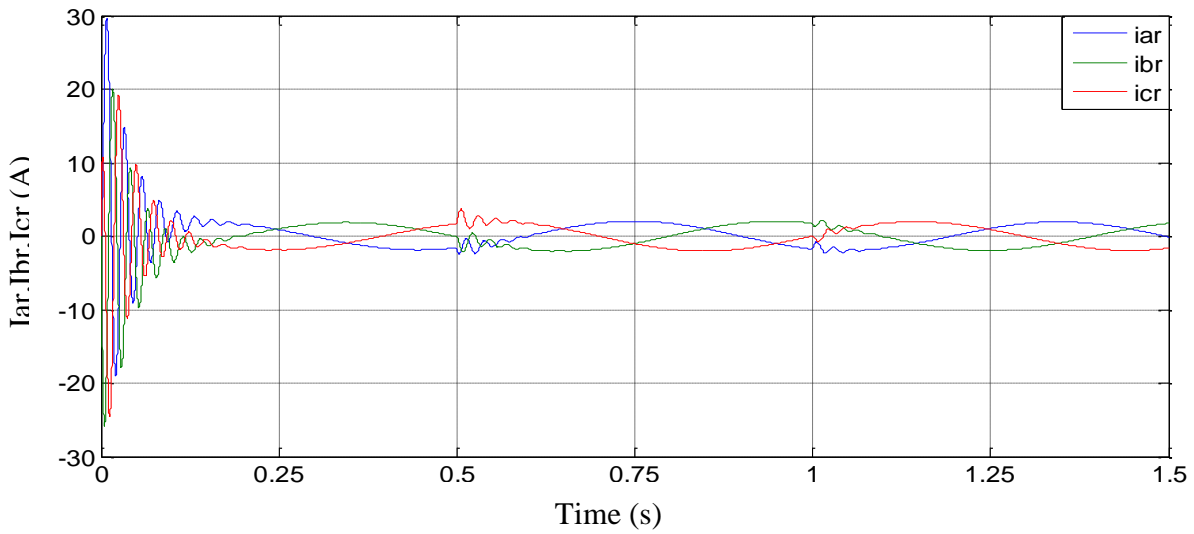

Figure 13. Rotor current

\subsection{Hyper-synchronous mode}

In this operating mode, it is assumed that the DSIG rotates above synchronous speed $(1648 \mathrm{rpm})$. The results obtained for this operating mode are as follows: 


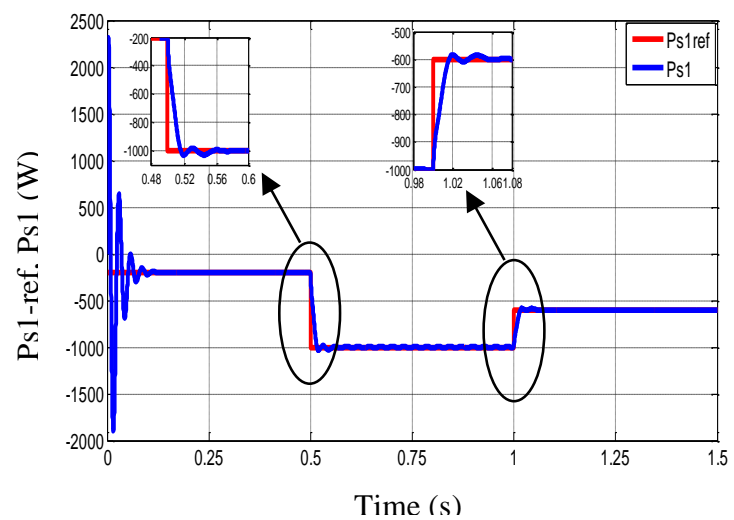

Figure 14. Active power of stator 1 and its reference

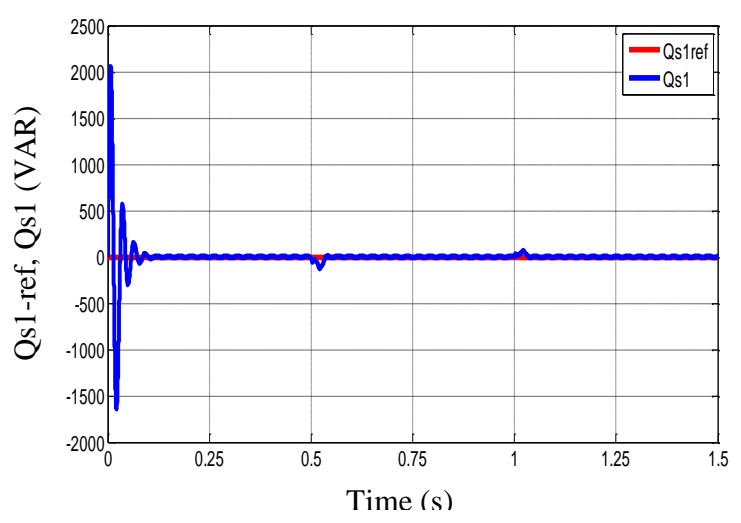

Figure 16. Reactive power of stator 1 and its reference

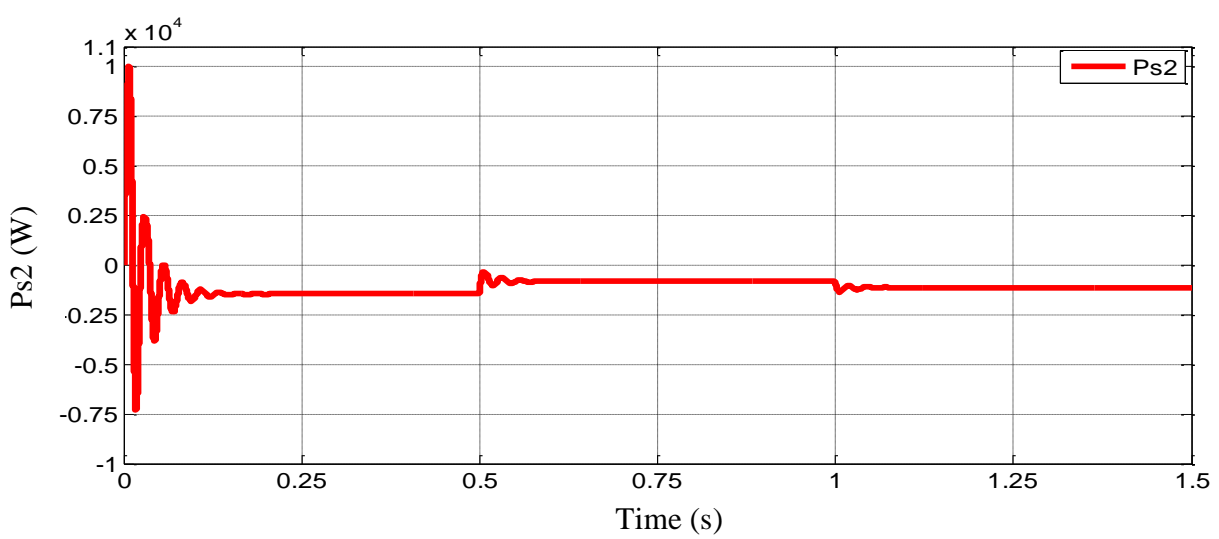

Figure 18. Active power of stator 2

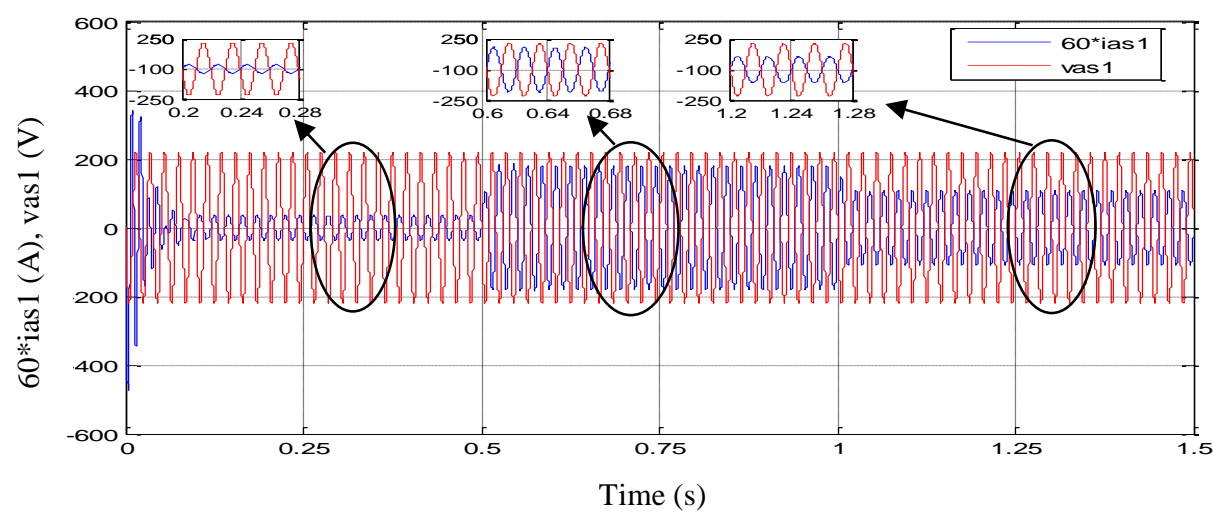

Figure 19. Current and voltage of stator 1 


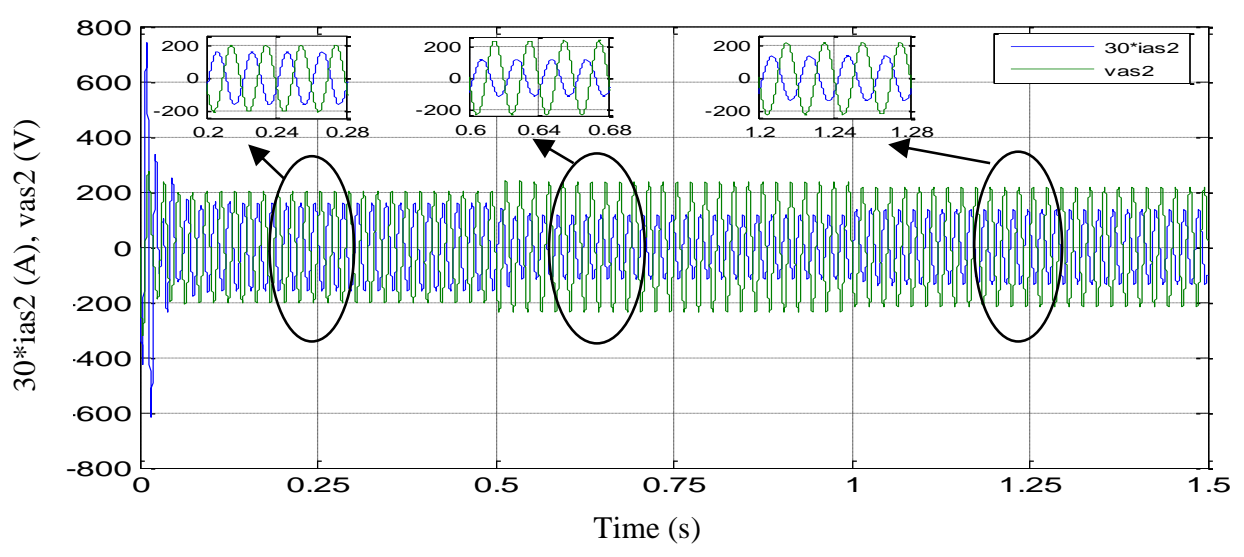

Figure 20. Current and voltage of stator 2

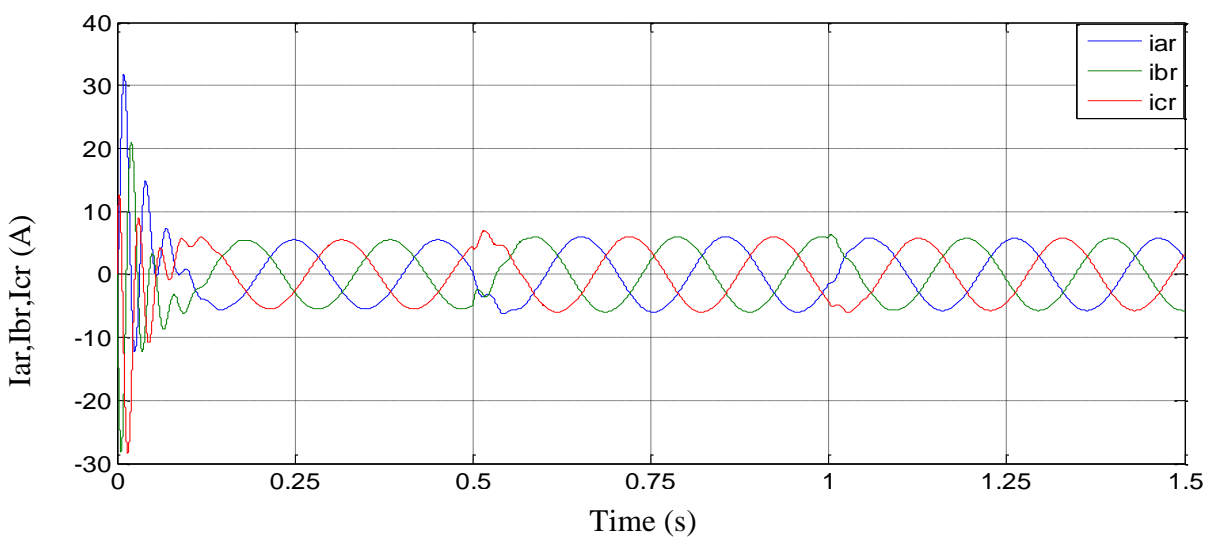

Figure 21. Rotor current

Figures 6, 8, 14 and 16 show that the active and reactive powers of stator 1 (power winding) follow perfectly their references in both hypo and hyper synchronous modes. A perfect decoupling between the active and the reactive powers exchanged between stator 1 and the grid is observed, where the quadrature component of stator 2 (control winding) current (Figures 7) controls the active power of stator 1 (Figure 6) and the reactive power (Figure 8 ) is controlled by the direct component of stator 2 current (Figure 9). This is du to the fact that the reference frame is aligned with stator 1 flux.The same remarks can also be drawn about the hypersynchronous mode considering Figures 14, 15 and 16, 17 respectively.

The positive sign of the active power of stator 2 shown in Figure 10 indicates that the DSIM operates at the hypo-synchronous mode and absorbs active power from the grid through stator 2 . Figure 12 shows the voltage and the current of stator 2 and their zooms, particularly the phase shift between them is also a proof that the DSIM operates at the hypo-synchronous mode.

The negative sign of the active power of stator 2 shown in Figure 18 indicates that the DSIM operates at the hyper-synchronous mode and provides active power to the grid through stator 2 . This can also be seen in Figure 20 considering the phase shift between the voltage and the current of stator 2.

In Figures 13 and 21, showing the rotor currents corresponding to the hypo and hyper synchronous modes respectively, we can see that the steady state rotor current magnitude and frequency are constants. This result is expected in accordance with the starting assumption stating that the speed and then the slip are constant. As can be noted in these figures, the frequency of the rotor current varies in accordance with the following relation-ship: $\omega_{r}=\omega_{s}-p^{*} \Omega_{r}=g * \omega_{s}$, where $\mathrm{g}$ is the slip. It can also be noted that the rotor current magnitude increases with the slip.

We can see in Figures 11 and 19 representing the current and the voltage of stator 1 corresponding to the hypo and hyper synchronous modes respectively, that the DSIM always provides power from stator 1. It can also be noted, by examining the zooms of the voltage and the current that the DSIM operates at a unity power factor. Examining Figures 11, 12 and 19, 20 simultaneously, we can note that stator 1 and stator 2 currents and voltages have the same frequency, this is due to the fact that stator 1 and stator 2 windings have the same number of poles. 


\section{CONCLUSION}

In this paper, the active and reactive power control of a $1.1 \mathrm{~kW}$ DSIM is studied. PI controllers are synthesized and a model of a controlled DSIM is developed in a Matlab-Simulink environment. Good performances are shown in the simulation results; they prove the feasibility and the validity of the proposed control method. The results obtained also prove that the controlled DSIM offers similar performances than those of the DFIM without any extra difficulties. The performances of the DSIM are particularly interesting in hyper synchronous mode. Indeed, in this region, the efficiency is better and the DSIM can participate in network system services.

Future work will focus on the robustness of the developed regulators and the integration of DSIM into a wind energy conversion system.

\section{REFERENCES}

[1] J. A. Barrado-Rodrigo, J. I. Talpone, and L. Martinez-Salamero, "Variable-speed wind energy conversion system based on a dual stator-winding induction generator," IET Renewable Power Generation, vol. 11, no. 1, pp. 73-80, 2017.

[2] Hossein Keshtkar, Hossein Abootorabi Zarchi, "Improved Design of a Dual Stator Winding Induction Generator for Wind Power Applications," $24^{\text {th }}$ Iranian Conference on Electrical Engineering (ICEE). IEEE 2016.

[3] M. Cheng, Y.Zu, "The state of the art of wind energy conversion systems and technologies : A review," Energy Conversion and Management, vol. 88, pp. 332-347, 2014.

[4] Z. Alnasir, M. Kazerani, "An analytical literature review of stand-alone wind energy conversion systems from generator view point," Renewable and Sustainable Energy Reviews, vol. 28, pp. 597-615, 2013.

[5] W. Hofmann, F. Okafor, "Doubly-Fed Full-Controlled Induction Wind Generator for Optimal Power Utilization," 4th IEEE International Conference on Power Electronics and Drive Systems, vol. 1, pp. 355-361, 2001.

[6] D. Cherifi, Y. Miloud "Analysis of Adaptive Fuzzy Sliding Mode for Nonlinear Control of the Doubly Fed Induction Motor," Indonesian Journal of Electrical Engineering Indonesian Journal of Electrical Engineering (IJEEI), vol. 6, no. 4, pp. 436-447, 2018.

[7] S. Tohidi, H. Oraee, M.R. Zolghadri, S. Shao, and P. Tavner, "Analysis and enhancement of low-voltage ride-through capability of brushless doubly fed induction generator," IEEE Transactions on Industrial Electronics, vol.60, no.3, pp.1146 -1155, 2013.

[8] M.Benakcha, L.Benalia, S.Azzouz, and F. Ameur, "Robust Control of a Dual Stator Induction Generator used in Wind Power generation," in Proc. of International IEEE Conference on Control, Automation and Diagnosis (ICCAD), pp. 174-179, Hammamet-Tunisia, 2017.

[9] T. Laamayad, F. Naceri, R. Abdessemed, and A. Boudiaf, "Fuzzy Adaptive Approach for Control the Dual Star Induction Machine," CIAM'2011, International Conference on Automation and Mechatronics Oran, November 2011, pp. 22-24.

[10] K. Nounou and K. Marouani, "Control of a dual star induction generator driven wind turbine," in Proc. IEEE SIELA, Jun. 2016, pp. 1-4.

[11] J. Poza, E. Oyarbide, I. Sarasola, and M. Rodriguez, "Vector control design and experimental evaluation for the brushless doubly fed machine," IET Elect. Power Appl., 2009, vol. 3, no. 4, pp. 247-256, 2009.

[12] X. Wei, M. Cheng, P. Han, W. Wang, and R. Luo, "Comparison of Control Strategies for a Novel Dual-Stator Brushless Doubly-Fed Induction Generator in Wind energy Applications," in Proc. IEEE Int. Conf. Elect. Mach. Syst, 2015, pp. 1039-1045, 2015.

[13] X. Wei, M. Cheng, J. Zhu, H. Yang, and W. Hua, "Model Predictive Power Control of a Brushless Doubly Fed Twin Stator Induction Generator," in Proc. IEEE Energy Convers. Congr. Expo. ((ECCE), 2017.

[14] S. Chekkal, N. Aouzellag Lahaçani, D. Aouzellag, K.Ghedamsi, "Fuzzy logic control strategy of wind generator based on the dual-stator induction generator," Electrical Power and Energy Systems, vol. 59, pp.166-175, 2014.

[15] L. Xu and P. Cartwright, "Direct active and reactive power control of DFIG for wind energy generation," IEEE Trans.Energy Convers, vol. 21, no. 3, pp. 750-758, 2006, https.

[16] R. Pena, J. C. Clare, and G. M. Asher, "Doubly fed induction generator using back-to-back PWM converters and its application to variable-speed wind-energy generation," IEE Proceedings - Electric Power Applications, vol. 143, no. 3, pp. 231-241, 1996, https.

[17] F. Mazouz, S. Belkacem, Y. Harbouche, R. Abdessemed, S. Ouchen, "Active and Reactive Power Control of a DFIG For Variable Speed Wind Energy Conversion," in Proc of 6th International IEEE Conference on Systems and Control, (ICSC'2017), Algeria, 2017.

[18] N.El Mouhi, A Essadki, "Active and Reactive Power Control of DFIG used in WECS using PI Controller and Backstepping," in IEEE 5th International Renewable and Sustainable Energy Conference (IRSEC), pp. 1-6, Morocco, 2017.

[19] M.Taleb, M.Cherkaoui, "Active and Reactive Power Control of Doubly Fed Induction Generator Wind Turbines to Answer Grid Codes Requirements,” Journal of Clean Energy Technologies, vol. 6, No. 2, pp.101-105, 2018.

[20] Boyette A, Saadate S, Poure P, "Direct and indirect control of a doubly fed induction generator wind turbine including a storage unit," in Proc. of the 32nd Annual IEEE Indust Electron conference IECON, pp. 2517-2522, 2006.

[21] B. Hamane, M. L. Doumbia, A. M. Bouhamida, M. Benghanem, "Direct Active and Reactive Power Control of DFIG based WECS using PI and Sliding Mode Controllers," 40th Annual Conference of the IEEE Industrial Electronics Society Journal (IECON 2014), pp. 2050 -2055, 2014. 
[22] Prangya Parimita Pradhan, Bidyadhar Subudhi, "Real-time Active and Reactive Power Control of a Doubly-Fed Induction Generator based Wind Energy Conversion System," in Proc. of the IEEE Region 10 Conference (TENCON), pp. 540 - 544, Malaysia, 2017.

[23] A. Tamaarat, A. Benakcha, "Performance of PI controller for control of active and reactive power in DFIG operating in a grid-connected variable speed wind energy conversion system," Front. Energy, vol. 8, no.3, pp. 371-378, 2014.

[24] D.K.Bhutto, Jamshed A.Ansari, F.Chachar, S.Katyara, J.Soomro, "Selection of optimal controller for for active and reactive power control of doubly fed induction generator (DFIG)," in Proc. of 2018 International Conference on Computing, Mathematics and Engineering Technologies (iCoMET), pp. 1-5, 2018.

\section{BIOGRAPHY OF AUTHORS}

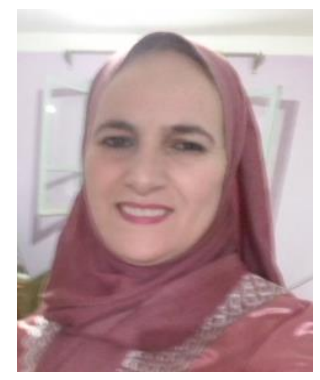

Fatma Lounas was born in Tizi Ouzou, Algeria. She received the BSC degree in Electrical Engineering from Mouloud Mammeri University of Tizi Ouzou, Algeria, in 1997 and the MSC degree in Electrical Engineering at the same University. Since 2011 she has been with the Mouloud Mammeri University of Tizi Ouzou, where she is currently a part time lecturer. Her main interests include power quality and electrical machine control.

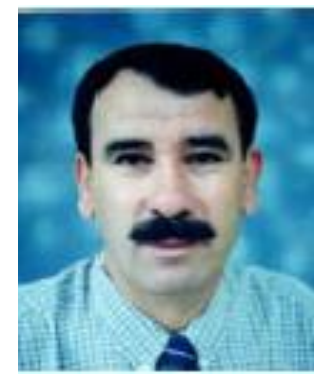

Salah Haddad was born in Tizi Ouzou, Algeria. He received the BSC degree in Electrical Engineering from Mouloud Mammeri University of Tizi Ouzou, Algeria in 1985 and the PhD degree in Electrical Engineering from Institut National Polytechnique de Lorraine, Nancy, France in 1991. Since 1991 he has been with the Mouloud Mammeri University of Tizi Ouzou, where he is currently a Professor. His main interests include power quality and electrical machine control.

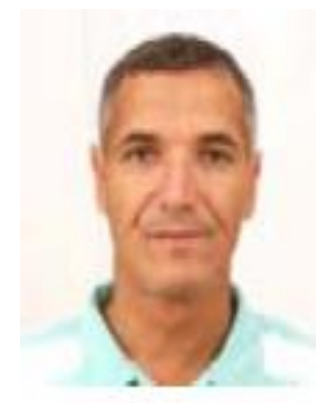

Nacereddine Benamrouche received his $\mathrm{PhD}$ degree in Electrical Engineering from the University of Sheffield, U.K. He worked as teaching assistant at the University of Leeds in 1990/1991, and as head of department in Najran Technical College of Technoloy, Saudi Arabia, from 2000 to 2004. He is currently a Professor at Elecrical Engineering Departement and a Director of "LATAGE" laboratory. His research interests include electrical machines and drives, power electronics and control systems. 